\title{
Tendencias Contemporáneas de la Filosofía Moral Briłánica*
}

\author{
Por Augusto Salazar Bondy
}

Tres eran las corrientes dominantes en la filosofía moral británica al finalizar el siglo XIX : el idealismo, tal como había sido formulado principalmente por dos grandes figuras universitarias : H. Bradley y Thomas H. Green; el evolucionismo, que precedía de la obra de Darwin y Spencer; y el utilitarismo, de antigua tradición británica, cuya versión más desenvuelta y meditada estaba constituída en esos momentos por los trabajos de Henry Sidgwick.

1.-La obra de G. E. Moore. En este panorama aparece hacia los comienzos del nuevo siglo un pensador que ha dejado una huella excepcionalmente profunda en la filosofía de lengua inglesa y al cual se remiten obligadamente comonpunto de partida - como término polémico, todos los investigadores que animan hoy el debate ético en la Gran Bretaña y los países anglosajones. Me refiero a George Edward Moore, quien fue profesor en la Universidad de Cambridge hasta su muerte, ocurrida en 1958, y cuyo libro principal, Principia Ethica, fue publicado en 1903 . Se ha dicho de Moore algo que raramente es válido para un pensador contemporáneo y que de seguro comporta el mejor elogio de su obra: que es ya un clásico de la filosofía. Este excepcional elogio no puede sorprender si se piensa en que la influencia de Moore ha alcanzado a figuras intelectuales de tan poderosa personalidad como Bertrand Russell y John Meynard Keynes. La fuerza suges-

- El presente trabajo desenvuelve el contenido de la conferencia sobre el tema pronunciada en el Instituto Cultural Peruano-Británico. 
tiva y renovadora del pensamiento de Moore, aunque se hace patente en el conjunto de su obra, es especialmente notable en la ética que fue uno de los principales centros de interés de su reflexión.

En Principia Ethica, Moore circunscribe rigurosamente el terreno de la filosofía moral. Tradicionalmente, piensa Moore, se considera que las cuestiones éticas son las relativas a la bondad de la conducta. La tarea del filósofo es determinar qué es una conducta buena o mala. Pero "buena conducta" es un concepto mixto, en el cual el componente decisivo es el término "bueno". De allí que -y en esto hay un rasgo típico de toda la metodología filosófica de Moore, cuidadosa siempre de le precisión lingüística- la determinación del uso de la palabra "bueno" sea la condición fundamental de la construcción de una ética filosófica. El filósofo debe plantear y responder la cuestión general: "¿Qué es bueno?" ("What is good?"), si quiere acceder al terreno propio de la investigación filosófica. Pero en el planteo mismo de esta cuestión hay ya un decisivo problema de determinación de sentido, cuya solución compromete toda la concepción de la ética. En efecto, según Moore, cabe entender esta pregunta hasta en tres sentidos, los cuales se hacen manifiestos considerando los diversos tipos de respuestas posibles a ella. Podemos responderla, en primer lügar, refiriéndonos a teonductas o hechos singulares que consideramos buenos; por ejemplo, a la acción que el alumno Pérez realizól Gril clase. Este sentido particular, referido a diversas situaciones y sujetos, no es el que, según Moore, debe tomar en cuenta la ética científica, porque el filósofo no se ocupa de casos singulares, ni su misión es dar consejos o hacer exhortaciones personales. En segundo lugar, la pregunta "¿qué es bueno?" puede ser respondida enunciando juicios morales como los siguientes: "el placer es bueno", "la piedad es buena", es decir, juicios en los cuales se hace referencia a determinados géneros de conductas o hechos. El sentido de "bueno" implicado en estos juicios sí interesa a la ética y su investigación ha sido desde la antigüedad tarea de la filosofía moral. Tomando en cuenta estos casos generales, la ética se vincula con la casuística moral y somete a crítica su fundamento. Pero hay un tercer sentido de "bueno" que pertenece sólo al dominio de la ética y es por tanto ajeno a la casuística. A él nos referimos cuando, preguntando "¿qué es bueno?", inquirimos por la definición de lo 
bueno, es decir, apuntamos, como hacía Sócrates, ya no a los casos concretos o los géneros de las cosas buenas, sino a la noción misma de lo bueno o el valor. Y este sentido de la interrogación acerca de lo bueno es según Moore el más importante para la refexión filosófica y constituye en verdad el tema central de la ética ${ }^{1}$.

El tratamiento sistemático de este tema ha sido el hilo conductor de toda la concepción del valor en Moore y también de su polémica con las posiciones axiológicas tradicionales. Moore, en efecto, combate tanto las posiciones subjetivistas y naturalistas cuanto las metafísicas. Sobre la base de un fino análisis del lenguaje y su uso ético y de la experiencia moral, complementado sagazmente con una exposición de las consecuencias sistemáticas del subjetivismo, el pensador de Cambridge muestra la insuficiencia de las posiciones axiológicas que intentan reducir el valor a predicados subjetivos, es decir, a propiedades vivenciales - actitudes que ocurren en las conciencias valorantes. De esta refutación, que es uno de los más sólidos elementos de su teoría del valor, Moore extrae la evidencia de que los enunciados valorativos tienen un referente objetivo diferente al de las aserciones sobre sentimientos, deseos o cualesquiera actitudes que pueda tener un sujeto o sobre las relaciones de este sujeto con el mundo. Dicho con otras palabras, descartar como significado de los juicios de valor el dominio psicológico no implica negarles objetividad, ni ponerlos fuerc delcalcance de las sexigencias formales de la lógica.

Pero esta reivindicación de objetividad no le parece suficiente a Moore. Considera que la demanda de verificación implícita en nuestros juicios morales y axiológicos lleva a algo más que al establecimiento de un valor "objetivo". Y es que los juicios de valor no son tampoco interpretables en términos naturalistas. Se explica así por qué quienes se oponen al subjetivismo rechazan también, las más de las veces, la fundamentación del valor según los principios de la ciencia natural, a pesar de que con tal fundamentación va aparejada la idea de la objetividad del valor. ¿Por qué se rechaza este objetivismo? Porque, piensa Moore, lo que realmente se busca no es sólo una fundamentación del va-

1. Cf. Principia Ethica, Cambridge, at The University Press, 1956, pp. $3-8$. 
lor objetivo, sino de1 valor intrínseco de las cosas. Lo que se quiere es fundar, como él dice, la "internalidad" del valor ${ }^{2}$.

De este modo, Moore introduce el concepto de valor intrínteco que ocupa un lugar dominante en toda su concepción axiológica y es sin duda una de sus más sugestivas aportaciones a la moderna teoría del valor. Sin descartar la existencia de otros sentidos de la palabra "bueno", como, por ejemplo, "buenol como medio", "bueno como parte", "bueno para alguien", "bueno esencial o cabalmente" (ultimately) o "bien último", y estando más bien inclinado a distinguir estos significados de la palabra "bueno" con respecto a "bueno intrínsecamente", Moore concentra toda su atención en la idea del valor intrínseco, concediéndole la máxima importancia para la ética. De allí que una y otra vez, a lo largo de su obra escrita, haya vuelto sobre esta idea en una paciente labor de análisis, variando sus enfoques y buscando formularla del modo más claro y riguroso posible. Vemos así que en Principia Ethica lo intrínsecamente valioso es considerado equivalente a lo "bueno en sí mismo", en contraste con lo "bueno como medio"4. Por otra parte, la pequeña Etica de 1912 caracterizaba de este modo el concepto del valor intrínseco: "al decir que una cosa es intrínsecamente buena, se quiere significar que sería bueno que la cosa en cuestión existiese, aun cuando existiese completamente sola, sin ningún acompañamiento o efecto posterior cualquiera: En un trabajo inmediatamente posterior, la "noción delvalor intrinsedo Sespone en relación con la de naturaleza intrínseca, en los siguientes términos: "Decir de un género de valor que es 'intrínseco' significa únicamente que la cuestión de si una cosa lo posee y en qué grado lo posee depende tan sólo de la naturaleza intrínseca de dicha cosa"6. En 1932, el ensayo "Is Goodness a Quality?" precisa una vez más el concepto, recurriendo a otro equivalente significativo: "Intrínsecamente bueno significa lo mismo que digno de tenerse por sí

2 "The Conception of Intrinsic Value", in Philosophical Studies, London, Routledge \& Kegan Paul, 1922, pp. 254-255.

3 Cf. Alan $R$ White, G. E. Moore. A Critical Exposition, Oxford, Basil Blackwell, 1958, pp. 118-122.

\section{Principia Ethica, p. 21.}

5 Cf. Etica, trad. cast., México, Editora Nacional, 1951, p 49.

B "The Conception of Intrinsic Value", In Philosophical Studies, p. 260 . 
mismo (worth having for its own sake)" ${ }^{\prime \prime}$. Esta nueva determinación de sentido obliga a Moore a restringir el uso de la noción de valor intrínseco a aquello que puede "tenerse" y, por esta vía, a enlazar directamente lo bueno intrínseco con el concepto de experiencia. Los problemas que así se planteaban y las dificultades con que tropezaba su intento de ofrecer una cabal determinación del sentido de "intrínseco", que Moore reconoce francamente en este y en sus anteriores ensayos, explican el nuevo cambio de enfoque que se percibe en el último escrito del filósofo de Cambridge, "A Replay to my Critics", en el que, volviendo en mucho a su posición de 1912, examina la caracterización comparativa según la cual decir que $\mathrm{X}$ es un mundo intrínsecamente bueno equivale lógicamente a decir que "sería mejor que tal mundo existiese, a que no hubiera enteramente mundo"s.

El núcleo de sentido que, a través de los diversos enfoques reseñados, Moore pone así de resalto en la idea de valor intrínseco es lo que podríamos liamar la autarquía de la cosa valiosa. Que una cosa tiene valor intrínseco significa que lo tiene en sí misma y que, en tanto se la busca, esta cosa es buscada estrictamente por sí misma. Su valor no sólo no depende pues del sujeto valorante, sino que ni siquiera está condicionado por las circunstancias reales. Sean cuales fueren esas circunstancias, si la cosa posee valor intrínsecamente, seguirá poseyéndolo aunque dichas circunstancias varien Co desaparezcan. Expresado de otro modo, la idea del valor intrínseee implica da pesibilidad de que aquello que lo posee sea pensado solo, sin nada más, y considerado bueno en este aislamiento.

Pero ¿cuál es el status ontológico de este valor que la cosa posee por sí misma? Moore lo caracteriza como una propiedad simple, aríáloga en esto a las propiedades sensibles como el color - aunque en otros respectos sea muy diferente, como hemos de verlo más adelante. De esta caracterización se desprenden varias consecuencias importantes. La primera es que, siendo simple la propiedáad de valor, no puede ser analizada; es un dato

7 In Philosophical Papers, London, George Allen and Unwin, 1959, p. 94 .

8 The Philosophy of G. E. Moore, ed, by P. A. Schilpp. The Library of Living Philosophers. $2^{\mathrm{a}}$ ed., New York, Tudor Publishing Company, 1952, p. 557. Cf. A White, op. cit., p. 141. 
último. La segunda consecuencia es que no puede ser definida, porque, según Moore, toda definición implica análisis, es decir, reducción de lo definido a sus componentes elementales. De allí el fracaso de todas las definiciones propuestas del valor, las cuales presuponen siempre, de una manera u otra, la noción que se quiere definir. $Y$ de allí, igualmente, el fracaso de toda demostración de las propiedades valorativas de un objeto, pues también el razonamiento implica análisis. Se hace patente de este modo una nueva y muy importante consecuencia de la caracterización de Moore, tocante al conocimiento axiológico. Sólo podemos conocer el valor por inspección directa, es decir, por intuición, como ocurre -confirmando la anclogía indicada arriba- con las cualidades sensibles. Quien no intuye el valor no puede conocerlo, pero quien lo intuye no necesita más para poseerlo cognoscitivamente, pues la aprehensión inmediata da con evidencia lo valioso del objeto.

Al interpretar el valor intrínseco como una propiedad que posee una cosa por sí misma, Moore no quiere sin embargo dar a entender que el valor es una propiedad constitutiva de la cosa. La analogía con los colores, o con cualquier otra propiedad natural empírica, cesa en este punto. Ninguna de esas propiedades es el valor. Nada que sea elemento constituyente de la cosa y que sirva para describirla puede identificarse con la propiedad de valor, ya que, según nuestro filósofo, el valor no permite describir la cosary eno puede por eso reemplazar a ninguna propiedad descriptiva, ni ser sustituída por ella o interpretada en términos de propiedades naturales. Hacer esto es incurrir en el principal vicio lógico que ha invalidado casi todas las teorías axiológicas, el paralogismo que Moore llama la "falacia naturalista" y que desde él ha sido un tema permanente de discusión en los círculos del pensamiento anglosajón.

La falacia naturalista consiste en reducir los valores a otras propiedades, como el placer, el interés o la adaptación al medio, confundiéndolos con ellas o haciéndolos lógicamente equivalentes a ellos y cambiando así subrepticiamente el asunto de la axiología y la ética. Cabe señalar que, para Moore, si bien esta falacia es cometida sobre todo por quienes, como los naturalistas, interpretan el valor en términos físicos, empíricos, también es común en las doctrinas metafísicas. En efecto, las axiologías metafísicas intentan reducir el valor a una instancia supraempírica o 
interpretarlo en términos de una realidad superior y distinta al dato axiológico estricto. En estas concepciones, como en las naturalistas, pese a las diferencias de contenido, el tratamiento del valor obedece así al mismo esquema reductivo. Para Moore, en cambio, el valor es un dato último, irreductible; no es nada constitutivo de las cosas, ninguna realidad empírica o metafísica, nada que componga como un ingrediente determinado la naturale$z a$ de la cosa, aunque dependa de ella y sólo de ella. Es una propiedad sí, pero no natural. De este modo, la doctrina de Moore, como consecuencia de su objetivismo internalista y su intuicionismo, se define también como una posición no naturalista.

De las premisas así establecidas parece seguirse una conclusión paradójica sobre la esencia del valor. Ocurre que, como hemos visto, el valor o lo bueno no es una propiedad constitutiva de la cosa, una propiedad en este sentido intrínseca del objeto; pero, puesto que depende de la naturaleza de la cosa y sólo de ella, puesto que la cosa lo posee en sí misma y lo seguiría poseyendo aunque variaran y desaparecieran todas las circunstancias y factores externos, es algo que pertenece intrínsecamente a la cosa. O dicho de otro modo, lo valioso no es una propiedad intrínseca, como lo son las naturales, pero en cuanto depende de las propiedades intrínsecas del objeto y sólo de ellas, le corresponde el status de lo intrínseco 9

Esta conclusión, amenazada porlacontradiccion que Moore honestamente ha presentgdo en todo sulproblematismo, mantuvo en el centro de su atención el tema del valor intrínseco y el problema de la objetividad de los juicios de valor y lo llevó en los últimos años a conceder mucho a las nuevas posiciones teóricas -que hemos de reseñar más adelante-, aunque sin abandonar definitivamente los puntos principales de su doctrina. Hasta qué punto era posible para él conceder la validez de ciertos argumentos que se le oponían sin por eso dejar de reconocer la parte de verdad que había en los suyos propios; hasta qué punto se situaba Moore de lleno en la encrucijada de la crítica y no se angustiaba por la problematicidad que ella mantiene viva, y también hasta qué punto su pensamiento era ejemplarmente honesto, lo muestran bien estos pasajes de su polémica con el americano Stevenson, defensor de la interpretación emocionalista subje-

9 Cf. "The Conception of Intrinsic Value", Phil. Studies, pp. 273-274. 
tivista de los conceptos éticos y axiológicos. "Siento ciertamente alguna inclinación a pensar que esto es verdad - dice refiriéndose a la tesis subjetivista de Stevenson- y que en consecuencia mi propio punto de vista anterior es falso... Pero, de otra parte, también siento alguna inclinación a pensar que mi anterior punto de vista es verdadero. Y si se me pregunta por cuál de estos incompatibles puntos de vista siento la más fuerte inclinación, sólo puedo responder que no sé ya si estoy más fuertemente inclinado a aceptar el uno que a aceptar el otro"10.

Dentro del cuadro general de esta sugestiva teoría del valor se articulan las principales tesis éticas de Moore. Aunque, como reflejo de su orientación axiológica dominante, el pensamiento ético de Moore está llevado a resaltar la función del valor de lo bueno y a interpretar a base de él otros conceptos morales, como lo recto y lo debido, en su obra llega a definirse bien un dominio propiamente ético y un conjunto de términos y cuestiones con sentido práctico espécifico. Ya en Principia Ethica, Moore había distinguido la cuestión ética valorativa, "¿qué es lo intríngecamente bueno?", de la cuestión práctica, también fundamental, "¿qué debemos hacer, qué acción es la correctu?" El segundo tipo de cuestiones implica juicios de valor relativos a lo que es bueno como medio y a lo que, en definitiva, es bueno intrínsecamente y comotal es perseguido. De allí se desprende el primado de la noción de lo bueno. La conducta moralmente válida se determina de Gquerdo a dasicensecuencias que de ella se derivan, a la bondad de sus efectos. Con esto Moore se sitúa en la línea del utilitarismo moral, caracterizado de manera general como una tesis que interpreta la validez moral de la conducta en razón de los efectos que de ella se desprenden. Pero se trata de un utilitarismo ideal, pues el término explicativo último es el valor intrínseco, lo bueno concebido en términos no naturalistas. La conducta humana debe propender a realizar el máximo bien intrínseco en el mundo, o sea, no una determinación ligada a ciertas circunstancias y por tanto condicionada, sino una instancia capaz de radicar en las cosas mismas aunque varíen o desaparezcan las circunstancias. Pero que con esto no estaba abandonando Moore el terreno de la vida humana concreta y personal para postu-

10 "A Replay to my Critics", op. cit., pp. 544-545. Cf. igualmente p. 554 . 
lar una vaga metafísica del bien, se hace patente claramente en una de las formulaciones que ofrece de las cosas que pueden considerarse intrínsecamente valiosas. Para el filósofo de Cambridge, lo intrínsecamente bueno es una instancia compleja que implica siempre una forma de conciencia y determinadas vivencias sentimentales, y entre los sentimientos así implicados, un cierto monto de placer. Lo bueno que persigue la conducta moral es pues una experiencia humana compleja, un todo consciente con elementos de placer.

Pero las determinaciones axiológicas, aunque son necesarias, no bástan para responder a las cuestiones éticas prácticas, aquellas que conciernen a lo debido y lo correcto. Porque aquí hay otro tipo de determinantes, de orden causal, que deben ser formulados a base de juicios empíricos sobre el estado del mundo. Para actuar correctamente debemos saber cuáles son los resultados valiosos que hemos de perseguir, pero también de qué manera podemos alcanzarlos. Y esto último depende de la penetración cognoscitiva en el orden del mundo, del aleance de nuestra previsión sobre los efectos de las acciones alternativas y de las causas exteriores. A diferencia de lo que ocurre con los juicios de valor, en los cuales por intuición llegamos a convicciones firmes, en las cuestiones prácticas estamos sujetos a la probabilidad y la determinación aproximativa. Moore piensa por ese que en este punto la ética no puede dar seguridades. Cuál sea la acción debida en cada caso es un problema que no puede resolverse" por evidencias definitivas, sino por la elaboración circunstancial y gradual de los datos disponibles.

2.-Otros intuicionistas. Al lado de Moore deben ser mencionados otros pensadores británicos representativos, con variantes particulares, de la misma línea de pensamiento. Son los principales entre ellos: Hastings Rashdall, autor de The Theory of Good and Evil (1907), de quien procede la denominación de "Utilitarismo ideal" aplicada a esta corriente; John Laird, autor, entre otros libros, de The Idea of Value (1928); y A. C. Ewing, docente en Cambridge en la actualidad, que se ha destacado como defensor del intuicionismo frente al subjetivismo y al naturalismo en los años recientes. En su debatido libro The Definition of Good, Ewing ha hecho un minucioso estudio de la significación del término inglés "good", llegando a distinguir hasta diez significados principales. Son éstos: $1^{\circ}$ "bueno" como equivalente a " $a$ - 
gradable (pleasant); $2^{\circ}$ lo que satisface los deseos; $3^{\circ}$ "bueno como medio", eficiente, en el sentido de hacer algo con eficiencia, cualquiera que sea el valor de esto; 4 ? "bueno como medio" para producir algo intrínsecamente bueno; 5 ? "eficientemente producido"; $6^{\circ}$ "intrínsecamente bueno", "bueno en sí mismo" y "bueno como fin"; 7 ? "bueno en esencia" o "cabalmente bueno" (ultimately good); 8 " "lo que hace bueno", (goodmaking), buen constituyente, aplicado a las cualidades que hacen buena a la cosa que las posee; 9 "moralmente bueno", $\alpha$ plicado a las acciones; y $10^{\circ}$ "moralmente bueno" aplicado a las personas. A estos diferentes sentidos de "good" corresponden otros tantos de bad ${ }^{11}$.

De acuerdo con Moore, Ewing considera el sentido $6^{\circ}$ de good, o sea, "intrínsecamente bueno", como el fundamental y le reconoce una función de primera importancia en la determinación de la validez de la conducta moral. Esta bondad intrínseca no es interpretable en términos naturalistas. Sin embargo, a diferencia de Moore y de otros intuicionistas, no cree Ewing que el concepto de lo bueno sea irreductible Hay otro concepto moral al cual puede ser reducido: el concepto de "deber ser" (ought). Según Ewing, en efecto, podemos definir lo bueno en términos de deber, como ocurre, v.g. en la siguiente formulación: "bueno es aquello respecto a lo cual debe tenerse una actitud positiva". Por su parte, "ought" puede entendersei en lsị (sentider más general, como adecuación o ajuste (fittingness), concepto al cual Ewing concede un papel fundamental en el lenguaje valorativo y moral, haciéndolo un término último, si bien reconoce la autonomía de otro sentido de "ought", el de obligación moral.

Con esta posición, Ewing tendía un puente entre el tipo de doctrina ética defendido por Moore y los utilitaristas ideales y las doctrinas de los deontologistas que hemos de considerar inmediatamente. En una obra publicada recientemente, Second Thoughts in Moral Philosophy (1959), esta actitud mediadora del pensamiento de Ewing se acentúa más y hace posible inclusive una nueva interpretación de ciertas tesis subjetivistas.

3.- Los deontólogos. Intuicionistas son también otros filósofos que sin embargo deben ser distinguidos por muchas razones de

11 The Definition of Good, N. York, The Macmillan Company, 1947, pp. 112-117. 
aquellos que hemos estudiado hasta aquí. Es el grupo de los filósofos llamados "deontólogos". El profesor Prichard de Oxford fue el primero en defender puntos de vista deontologistas en su famoso artículo "Does Moral Philosophy Rest on a Mistake?", publicado en 1912. Sin embargo, la importancia de la obra de Prichard y la novedad de planteo que traía consigo sólo fueron justamente estimadas más tarde, cuando otros pensadores elaboraron y defendieron posiciones semejantes. Los más conocidos entre ellos son: E. F. Carritt, C. D. Broad, Daiches Raphael y David Ross. Este último es un notable investigador en el campo de la historia de la filosofía y también el más completo y sistemático defensor del deontologismo. Ross ha publicado dos valiosos libros de ética: The Right and the Good (1930) y Foundations of Ethics, (1939), a los cuales nos referimos principalmente para estudiar esta posición, sin perjuicio de ilustrarla también por medio de la obra de los otros investigadores que hemos mencionado.

Los deontólogos son objetivistas convictos y confesos. Afirman que lo bueno, lo justo, lo recto y, en general, todos los predicados morales son determinaciones que existen por sí y se imponen al sujeto. Esta existencia no es para ellos, como tampoco lo era para Moore, la de las propiedades naturales, ni puede reducirse a éstas. Son pues también no-naturalistas y lo son quizá en un sentido más radical, puesto que, como hemos de ver, no consideran pertinente, para la evaluación moraldel Bos resultados de la conducta, el bien que ella realiza, sino sólo su gdecuación a la norma, al principio del deber. Su posición es también en general intuicionista, pues, según ellos, el principio moral se aprehende directamente, con toda la inmediatez y la fuerza de evidencia que tiene el conocimiento intelectual. Prichard, por ejemplo, como lo sugiere el título del artículo que mencionamos, considera que la filosofía moral anterior ha reposado en un grave error de principio: el creer que cabe preguntarse por las razones por las cuales debemos cumplir una obligación. Bien planteadas la cosas, ésta es una pregunta que nadie puede responder; pero tampoco hace falta responderla, pues vemos siempre con evidencia cuál es nuestra obligación. Intuir una obligación como tal y aceptarla es una y la misma cosa. Quien no la ve, no puede reconocerla y nadie puede por tanto demostrársela ${ }^{11 a}$.

11a Cf. H. A. Prichard, Moral Obligation, Oxford, The Clarendon Press, 1957, p. 8. 
Este atributo de inmediatez propio del conocimiento moral, especialmente en lo que concierne a los deberes y las obligaciones, es también puesto de resalto con toda claridad por Ross. Dice en Foundations of Ethics: "Cuando consideramos un acto particular como el de mentir, el de quebrar una promesa o el causar dolor gratuitamente, no necesitamos referimos - ni lo hacemosa un principio general que podemos recordar; vemos que el acto individual es, por su propia naturaleza, incorrecto ${ }^{12}$.

Los deontólogos afirman pues la validez necesaria de los enunciados morales; pero además insisten en que esta necesidad no es inferencial, sino intuitiva. Las normas supremas no requieren ser derivadas de otras enunciaciones para imponerse a nuestro conocimiento como válidas; su validez es inmediata. De allí que la analogía obligada a que recurran sea la aprehensión de los axiomas matemáticos. Veamos un texto de Ross, muy ilustrativo a este respecto: "Si preguntamos cómo llegamos a conocer estos principios morales fundamentales, la respuesta me parece ser que esto ocurre del mismo modo como conocemos los axiomas de las matemáticas. Ambos me parecen ser por igual sintéticos y a priori; o sed que vemos que el predicado, aunque no esta incluído en la definición del sujeto, pertenece necesariamente a cualquier cosa que satisfaga dicha definición. Y, al igual que en matemáticás, por-inducción iñtuitiva captamos las verdades generales. Vemos, por ejemplo, que un acto particular que imaginamos, el cuar'es cabazl de producir agrado (plaesure) a otra persona,nos impone una exigencia, y solo hay que dar un corto e inevitable paso desde esta aprehensión hasta ver que todo acto que posea el mismo carácter constitutivo debe tener el mismo carácter resultante de rectitud prima facie"1s.

Encontramos aquí una expresión que tiene especial interés para el estudio de la polémica intuicionista. Ross habla, al final del texto que hemos citado, de "rectitud prima facie". Para entender esto, debemos referirnos a las objeciones hechas a la tesis de que poseemos una intuición a priori de lo que es recto. Estas objeciones son muy poderosas, sobre todo por la evidencia de las múltiples excepciones que pueden encontrarse a la validez

12 Ross, Foundations of Ethics, Oxford, at the Clarendon Press, 1939, p. 173.

13 Foundations, p. 320. Cf. The Right and the Good, Oxford, The Clarendon Press, 1930, pp. 29-30. Cf. asimismo Prichard op. cit., p. 8. 
de los principios morales. Por ejemplo, no parece imposible que en determinada circunstancia, como las de la mentira piadosa, la regla de "no mentir" sea infrigida y que la acción que la infringe, en el caso considerado, no sea incorrecta. Lo mismo puede decirse de todos los otros principios morales. Ante estas objeciones, Ross, así como el más joven de los deontologistas que hemos mencionado, Daiches Raphael (The Moral Sense, 1947), han distinguido lo "propia o totalmente recto" de lo "prima facie recto", o sea, de un lado, el género de acciones que en todos los casos poseen rectitud $y$, de otro, las acciones que propenden a la rectitud ${ }^{14}$. Basados en esta distinción, responden a las objeciones antes señaladas afirmando que si bien no siempre podemos ver por intuición $\alpha$ priori si un acto posee rectitud en un sentido pleno $\mathrm{y}$ total, pues habría que considerar todas las circunstancias del acto $y$ sus consecuencias, podemos en cambio ver intuitivamente que dicho acto es prima facie recto, es decir, que propende a ser una acción justa. No podemos aprehender con evidencia, por ejemplo, que toda acción que rompa una promesa sea incorrecta, pero sí que tiende a la incorrección moral y podemos atenernos a este conocimiento para guiar nuestra propia conducta.

Las consecuencias de esta modificación de la tesis intuicionista se advierten claramente. No disponemos ya de ese criterio absoluto de decisión acerica de le obligatorio de los actos que la intuición a priori estaba llamada a proporcionarnos. El propio Ross ha admitido que, si bien sabemos que ciertas acciones son prima facie obligatorias, no poseemos un conocimiento seguro sobre el grado de su obligatoriedad, el cual queda librado a las opiniones particulares. De este modo, en más de una ocasión, ante las exigencias en conflicto de varias acciones prima facie obligatorias, cada cual debe decidir, no por una intuición objetiva e

14 Cf. Ross, The Right and the Good, pp. 19 ss. En la caracterización del segundo tipo de actos, Ross y Raphael coinciden con la idea expuesta por Broad, otro de los deontologistas, acerca de la existencia de una tendencia de ciertos actos a ser rectos, haciendo patente una clara convergencia de conceptos en este círculo de reflexión ética. Cf. C. E. M. Broad, Five Types of Ethical Theory, London, Kegan Paul, 1930, p. 222; y Thomas E. Hill, Contemporary, Ethical Theories, New York. The MacMillan Company, 1959, p. 334 . 
indubitable, sino apelando a lo que Ross llama "el sentido individual de la fuerza relativa de las varias exigencias"15. Por su parte, Raphael, reflejando esta problemática del deontologismo, abandona el criterio de la intuición y caracteriza su posición, en una obra más reciente (Moral Judgement, 1955), como "deontología sin intuicionismo".

Un aspecto particular digno de considerarse en la posición axiológica de los filósofos que estamos estudiando es la negación de objetividad a los predicados estéticos, que se sostiene sin perjuicio del carácter objetivo de los enunciados éticos. Los deontólogos son, según esto, objetivistas en ética pero subjetivistas en estética. Asi, Ross sostiene en The Right and the Good que las cosas llamadas bellas no poseen ningún atributo común, aparte del poder de producir goce estético ${ }^{16}$, con lo cual descarta la existencia de una propiedad o conjunto de propiedades correspondientes al concepto de valor estético. Por su parte, otro deontólogo, Carritt, sostiene en su Introducción a la estética que, al depender la belleza de la significación que las cosas tienen para los sujetos, "la belleza no es una cualidad que realmente tenga (la cosa), sino sólo su posibilidad para llegar a ser significante de algun modo para cualquiera de nosotros"17. Y en su último libro, Ethical and Political Thinking, ratifica este punto de vista al considerar falsas las aserciones estéticas que gtribuyen a las cosas cualidades independientes del pensamiento $\circ$ el sentir de una persona ${ }^{18}$.

Aunque esta disparidad de puntos de vista no sea nada insólito en la historia de la filosofía, cabe preguntarse cómo es posible adoptar estas dos posiciones axiológicas simultaneamente, sin cuidarse de la coherencia sistemática del dominio del valor y $\sin$ afectar el fundamento de la ética. En el caso de los deontólogos, la explicación puede encontrarse en el tipo de doctrina ética que ellos defienden. Considerar esta explicación será, por

15 Foundations, pp. 188-189. Cf. Paul Edwards, The Logic of Moral Discours, Glencoe, Illinois, The Free Press, 1955, pp. 101, ss.

16 The Right and the Good, p. 128.

17 Introducción a la estética, trad. cast., México, Fondo de Cultura Económica, 1951 , p. 30.

18 Ethical and Political Thinking, London, Oxford Univ. Press, 1947, p. 30 . 
lo demás, una buena manera de llegar a un punto que me interesa subrayar aquí, la diferencia entre estos filósofos y los intuicionistas del tipo de Moore o Rashdall. En efecto, los deontólogos pueden sostener una tesis objetivista en ética y, no obstante esto, interpretar de modo subjetivista los fenómenos y enunciados estéticos, porque para ellos los conceptos éticos fundamenta les no pertenecen al orden de los valores de lo bueno y lo malo. Considerando su orientación general -no sus tesis particulares, que son en mucho dispares y tienen un condicionamiento histórico diferente-, el deontologismo se sitúa en la línea de la ética kantiana, en cuanto considera que no es el bien logrado sino la estructura legal de la conducta lo éticamente importante. La moralidad tiene sus propias bases, independientes del orden de lo valioso concreto y de las realizaciones buenas en el complejo de la existencia. La intuición ética logra sus mejores resultados cuando se refiere a lo correcto y el deber y permite por esto formular conceptos y enunciados con gran precisión, al paso que el concepto de lo bueno es equívoco y variable, a tal punto que, como lo expresa Carritt, "ordinariamente es mejor evitar el término de bueno en ética"19.

Desde la perspectiva de la autonomía así afirmada se comprende bien el rechazo de todo intento de formular los conceptos de corrección moral $\mathrm{Y}$ debèronetérminos de bondad que es otro rasgo típico de los deontologistas. Cuando Prichard se demandaba si la ética debía estar fundada en un error, tenía en mente esta independencia de los juicios básicos morales con respecto al valor de los resultados obtenidos. El error que quería evi. tar y en el cual, según el punto de vista de esta crítica, incurren por igual los utilitaristas empíricos y los ideales, era en buena cuenta el hacer depender la rectitud de la acción de las condiciones y efectos exteriores de su ejecución, los que, de ser tomados en consideración, como en ese caso habrían de serlo, imposibilitarían el conocimiento inmediato y absoluto de la validez de la conducta. Para Prichard, en cambio, así como para la mayoría de los deontologistas, una acción no es recta por sus consecuencias sino por su estructura legal, o sea, por sí misma.

19 The Theory of Morals, London, Oxf. Univ. Press, 1928, p. 48 . Carritt ha dedicado especial atención al tema del significado de "good", particularmente en su estudio An Ambiguity of the Word Good (1937). 
En tanto $y$ en cuanto se adecúa a una norma establecida y reconocida como válida, le corresponde la cualidad de rectitud y puede ser juzgada certeramente como moralmente válida por si misma.

Por contraste con las éticas teleológicas, el deotologismo se definía así claramente como una teoría según la cual las acciones rectas pueden conocerse y validarse con independencia del valor de sus resultados 0 , para decirlo con las palabras de Broad, como una teoría según la cual existen ciertos juicios éticos de la forma: "tal genero de acción será siempre recta (o incorrecta) en tales y tales circunstancias, a despecho de cuáles puedan ser sus consecuencias" ${ }^{\prime 20}$. De allí la posibilidad de sostener un objetivismo ético $\sin$ necesidad de asegurar un status común objetivo del valor, ni cuidarse de establecer un cuadro general y coherente de todo el dominio axiológico.

Con lo anterior no se quiere por cierto dar a entender que, a juicio de los filósofos que hemos considerado, el bien no sea un concepto de importancia para la ética, ni que en la determinación de la validez de la conducta no influya muchas veces la estimativa de las consecuencias. Hay inclusive deontologistas, como es el caso de Broad, que en más de un punto adoptan posiciones transigentes con qiertas tesis utilitaristas. Sin perjuicio de todo esto, to que interesa es resaltar lo típico del deontologismo, es decir, la especial relevancia y la autonomía acordadas a los conceptos de rectitud y deber en la interpretación de la vida moral y la tesis de que es imposible definir estos conceptos por medio de predicados de bondad.

4.-Bertrand Russell y el subjetivismo. Oponiéndose abiertamente a los puntos de vista sostenidos por las teorías éticas consideradas hasta aquí, cuyo denominador común, como hemos visto, es un claro objetivismo ético y la creencia en la existencia de un genuino saber moral fundado en la intuición, surgen desde los primeros años del presente siglo otras corrientes de pensamiento axiológico que han influído fuertemente en la filosofía anglosajona. Estas corrientes se entroncan con la vieja tradición empirista británica y, al mismo tiempo, con el movimiento filosófico neopositivista que tuvo su punto de partida en el famoso círcu-

20 Broad, Five Types of Ethical Theory, p. 206. 
lo de Viena. Conviene recordar que el inspirador de este movimiento filosófico, el gran filósofo austriaco Ludwig Wittgenstein, ejerció por largos años la docencia en la Universidad de Cambridge, donde difundió su filosofía terapéutica o logoterapia, cuyo designio principal era eliminar los pseudoproblemas filosóficos por el análisis del lenc;uaje. El pensamiento de Wittgenstein, sin embargo, procedía en buena parte de la reflexión de un filósofo británico, cuya obra está presente a lo largo de todo el debate doctrinario de este siglo: Bertrand Russell. Y Justamente Bertrand Russell se ofrece como uno de los más caracterizados defensores de una de las corrientes éticas a las que arriba me he referido, la subjetivista, que ahora quiero pasar a reseñar.

En sus primeras obras, el pensamiento moral de Russell se mueve en la dirección trazada por la obra de Moore. "En todas las cuestiones fundamentales de la filosofía - declaraba en 1903, en el Prefacio de Principles of Mathematics-, mi posición, en todos sus rasgos principales, deriva de G. E. Moore". Su libro de 1910, Philosophical Essays, lo presenta todavía en ese campo doctrinario. Lo bueno es para él una cualidad simple que pertenece al mundo, y lo correcto de la acción moral puede ser determinado por un cálculo de bienes; descansa en el máximo bien posible que se puede esperar como efecto de dicha acción ${ }^{21}$.

Pero estos puntos de vistoo encuadrados dentro del objetivismo axiológico, no son ni con mucho los más característicos de la reflexión ética de Russell. En efecto, a lo largo de su obra ulterior, él se ha singularizado más bien como defensor de tesis de signo contrario, cuya orientación general, aunque coincidentes en muchos puntos con las de ciertos positivistas lógicos, es la de un subjetivismo de cuño personal. Esta posición se hace presente con claridad en el ensayo What I believe (1925), donde Russell sostiene que son nuestros deseos los que confieren valor a las cosas, interpretando así el valor como una cualidad relativa al sujeto, a manera de las cualidades terciarias de que han hablado algunos axiólogos 22 . En An Outline of Philosophy, publicado poco después, el concepto de obligación es caracterizado en términos

21 Cf. in Philosophical Essays, "The Elements of Ethics". London, Longmans \& Green, 1910, p. 32.

22 What I Believe, London, Kegan Paul, 1925, p. 17.

28 An Outline of Philosophy, London, Allen \&Unwin, 1927, p. 234. 
decidídamente opuestos al objetivismo: "Que yo deba hacer algo -escribe Russell allí- significa primariamente: "éste es el acto hacia el cual yo siento la emoción de aprobación' ${ }^{23}$. Lo bueno moral resulta así no una propiedad de determinadas acciones, sino una secuela de las vivencias experimentadas por el sujeto.

El libro Religion and Science, publicado en 1935, ofrece una versión más amplia y elaborada de esta posición. Allí Russell pone la ética fuera del dominio del conocimiento y declara imposible todo intento de distinguir por su certeza los juicios morales $\mathrm{y}$, en general, cualquier juicio de valor. No hay enunciados éticos verdaderos o falsos en sentido estricto. Toda afirmación o negación relativa a lo bueno o lo malo pertenece a una esfera distinta a la del conocimiento de la verdad: "cuando afirmamos que esto o aquello tiene 'valor' escribe Russell-estamos dando expresión a nuestras propias emociones, no a un hecho que seguiría siendo cierto aunque nuestros sentimientos personales fueran diferentes" ${ }^{\prime 24}$.

Lo bueno y lo malo son pues asunto de sentimientos; pertenecen al dominio de las vivencias, no de las verificaciones fácticas. Para sostener esta tesis, Russell se remite a la vinculación estrecha que hay entre valorar y desear. Se podría decir - piensa él- que lo que deseamos todos es bueno, y es en cambio malo aquello que todos tememos. E1 problema reside $-\mathrm{y}$ aquí comienzan las bomplidariones para la éticaseren que los deseos de los hombres no coinciden, sino que, por el contrario, contrastan y se oponen grandemente de sujeto a sujeto. "La ética es un intento... de escapar a esta subjetividad", "un intento de prestar significación universal, y no meramente personal, a ciertos deseos nuestros", pero un intento "no coronado por el éxito"25. Pero ¿no hay nada, más allá de los sentimientos y deseos, una instancia capaz de decidir entre las convicciones subjetivas y que pueda fundar el juicio moral? Russell lo niega, porque descarta la posibilidad de encontrar argumentos aptos para probar que algo tiene valor por sí mismo, un valor intrínseco, como diría Moore. La intuición axiológica, a la que se pretende recurrir en reemplazo de la argumentación, supone un acuerdo entre los sujetos que es

24 Religión y ciencia, trad. castellana, México, Fondo de Cultura Económica, 1951, p. 142. 
justamenté lo que se echa de menos en el caso del valor. A diferencia de lo que ocurre con la intuición visual, no podemos calificar a nadie de "ciego para los valores", pues no se dispone de ningún otro medio para ratificar lo que se intuye $o$, en caso contrario, la incapacidad de intuir. En efecto, si bien al ciego para los colores no podemos probarle que el pasto es verde y no rojo, pues la evidencia necesaria proviene de la intuición que le falta, sí hay varias maneras de probarle que está ciego, es decir, que carece de esa capacidad de ver que la mayoría de los hombres poseen ${ }^{26}$. Al no existir estos medios complementarios en el caso de la aprehensión del bien y los valores, es ilusorio recurrir, como criterio de decisión, a una supuesta intuición axiológica. La conclusión que Russell extrae de aquí no deja lugar a confusiones: "Puesto que no hay aún manera de imaginar cómo decidir una diferencia de valores, la conclusión forzosa es que la diferencia es de gusto, no respecto a ninguna verdad objetiva"27.

El hablar de juicios morales verdaderos o falsos objetivamente es entonces un error, producto de una confusión de los enunciados éticos con los enunciados susceptibles de verificación. Cuando "un filósofo dice 'la belleza es el bien', puedo interpretarlo como si dijera 'jojalá todos amaran lo bello!' .... 'yo deseo que todos amen lo bello". Ahora bien, según Russell, estas dos posibilidades de interpretación del sentido de los enunciados éticos y axiológicos permiten establecer una diferenciá- fógica esencial: "la primera oraciónong hace cringuna aserción pero expresa un deseo; puesto que no afirma nada, es lógicamente imposible que pueda haber prueba en favor o en contra de ella, 0 que posea verdad o falsedad. La segunda oración, en vez de ser meramente optativa, hace una afirmación, pero que se refiere al estado de ánimo del filósofo, y sólo puede ser refutada por la prueba de que éste no tiene el deseo que dice tener. Esta segunda oración no pertenece a la ética sino a la psicología o a la biografía. La primera oración, que pertenece a la ética, expresa un deseo de algo, pero no afirma nada"28.

Los enunciados éticos $y$, en general, los juicios de valor traducen pues los deseos del sujeto, son reflejo de su mundo inter-

\footnotetext{
26 Ibid., p. 147.

27 Ibid., p. 147.

28 Ibid., p. 145-146.
} 
no y no pueden, en consecuencia, aspirar a ninguna validación objetiva. Con ello, la reflexión de Russell se aproximaba a los puntos de vista sostenidos por los positivistas lógicos y mostraba también más de una coincidencia con la posición nominalista de Ayer, que hemos de estudiar luego. Sin embargo, según su propia opinión, defendía una posición subjetivista. "La doctrina por la que he estado abogando - dice en Religion and Science- es una forma de la 'subjetividad' de los valores" 29 . Y esta es seguramente la manera más correcta de identificar su punto de vista, pues aunque Russell oscila en ler determinación precisa del status del valor, que refiere unas veces a deseos, otras a sentimientos, otras a vivencias de "gusto" o aprobación, en todos los casios sin embargo pone el acento en la función dominante de la subjetividad en el origen del valor ${ }^{30}$. Esto es confirmado por las obras posteriores de nuestro filósofo, en las que se ha querido encontrar una vuelta al punto de vista objetivista ${ }^{31}$. Tal es el caso del libro Human Society in Ethics and Politics, aparecido en 1954. Allí, Russell acepta la existencia de proposiciones éticas susceptibles de ser consideradas verdaderas o falsas, en sentido análogo a las proposiciones científicas. Sin embargo, lo que en realidad Russell califica de proposiciones verdaderas o falsas son enunciados empíricos acerca del comportamiento social o humano común, definiciones de términos éticos o proposiciones derivadas. En ninguno de estos casos, se tratc deljucios de valor en sentido estricto. Por lo demás "en ese libreiRussell insistesen la función que la aprobación tiene en la determinación del valor ético de las acciones y los fines y, de acuerdo con Sidgwick, concede gran importancia al placer como determinante de la aprobación, a lo cual agrega la inteligencia y la sensibilidad estética. Con semejantes tesis no había trascendido en nada los límites del subjetivismo.

Antes de terminar esta breve exposición del pensamiento axiológico de Russell, quiero detenerme en cilgunas conclusiones de su doctrina ética. Podría preguntarse: ¿se sigue de las tesis de Russell una negación del deber y el bien y, en suma, de la mo-

29 Ibid., p. 146.

30 Sobre este tema, cf. Hill, op. cit., p. 13, y Edwards, op. cit., p. 46.

31 Véase por ejemplo el estudio de Leon Dujovne sobre la axiología de Russell en Teoría de los valores y filosofia de la historia, Buenos Aires, Ed. Paidos, 1959, cap. II, especialmente pp. 59 y ss. 
ralidad? Esta idea está implícita en muchas de las objeciones hechas a su filosofía. Russell no cree, sin embargo, que tan graves consecuencias se sigan de sus tesis, puesto que ellas no anulan el concepto de obligación ( $y$ por tanto las determinaciones de la moralidad que se derivan de él), sino que tan sólo exigen interpretarlo en términos nuevos, en términos justamente de vivencias de deseo y aprobación. En cambio, los conceptos de pecado y sanción sí son eliminados. Puesto que no hay ningún criterio objetivo de lo bueno y lo malo, ninguna conducta puede ser considerada pecaminosa en sentido estricto, ni por ende susceptible de pena. Pero con esto, piensa Russell, tampoco se destruye la moralidad, toda vez que en nada se debilita el sentido del deber. Lo que se hace es poner la moralidad sobre sus justas bases, las de la vivencia personal, sin las cuales ninguna educación moral y ninguna orientación de la conducta social puede tener éxito. En efecto, ante un conflicto de opiniones éticas, puesto que su base de sustento es el deseo/ no hay instancia que resuelva. En la medida en que los deseos se oponen, cualquier prédica es impotente. Lo que hay que hacer entonces es tomar a cargo los deseos y trabajar por su modificación; influir en ellos, para influir en la conducta moral ${ }^{32}$. Se dirá quizá que sin la sanción del bien absoluto, los deseos son irracionales. Pero esta opinión le parece a Russell una simple consecuencia de la creencia en los valores objetivos. Privados de ese supuesto fundamento objetivo, los deseoșngetieneniperl quérserrconsiderados "irracionales", en el sentido negativo de la expresión. En nuestra experiencia personal tropezamos siempre con un bien que es deseado por sí y sin razones, pero esto no hace inferior al deseo que tiende a él, ni le quita dignidad.

Como un rasgo interesante de este enfoque ético, cabe señalar que Russell no tiene por iguales todos los deseos. Según él, algunos son egoístas y otros más generales o impersonales y generosos. Sin por cierto poder encontrar argumentos en su propia teoría a favor de esta tesis, cree que estos últimos-que, por lo demás, según Russell, no son tan raros en la humanidad- llevan a un mejoramiento ético. Fomentándolos, podemos hacer que los hombres "puedan ser llevados a actuar, más que en el presen-

82 Ibid., p. 149.

s3 Ibid., p. 149. 
te, de acuerdo con la felicidad general de la humanidad"33. El hablar de deseos superiores, de mejoramiento ético y por tanto de valoraciones altas y bajas - que es rasgo constante de las obras morales y de crítica social de Russell- planteaba un difícil problema a la posición subjetivista. Que nuestro filósofo ha sido consciente de esta aporía y de la necesidad de ir más allá de la teoría del deseo lo muestran sus reflexiones recientes sobre los tópicos de ética y axiología contenidas en A Replay to my Critics"s, donde se declara insatisfecho con la explicación defendida por él, aunque no llega a proponer una teoría sustitutoria.

Las tesis subjetivistas han sido elaboradas de modo sistemático y desenvueltas en diversas direcciones particulares por otros pensadores vinculados a diferentes ć́rculos del pensamiento anglosajón. A manera de ilustración de estos desarrollos, cabe mencionar a Alexander Sutherland $y$ Alexander Shand, quienes, interesados como están en la psicología de la conducta moral, ponen de relieve el papel del instinto y los sentimientos en el establecimiento de los conceptos éticos; al finés Edward Wastermarck, quizá el más influyente de los subjetivistas contemporáneos, quien ha desarrollado, en sus libros The Origin and Development of Moral Ideas (1906), Ethical Relativity (1932) y Christianity and Morals (1939), una axiología relativista que funda los conceptos éticos en las emociones de aprobación y desaprobación, al concebirlos como generalizaciones derivadás de ellas, sin por eso anular la posibilidad de establecer la verdad o la falsedad de los enunciados morales; a W. R. Lamont, defensor de un subjetivismo axiológico ligado a un punto de vista idealista en moral (The Principles of Moral Judgement, 1946; The Value Judgement, 1953); y a F. R. Tennant, cuyo libro principal, Philosophical Theology (1928), concllia una axiología del interés con los postulados básicos de una metafísica teísta ${ }^{35}$

5.-El nominalismo axiológico: Altred J. Ayer. Un rechazo tajante del objetivismo $y$, a la vez, una no menos decidida descalificación del subjetivismo, por lo menos en su forma ordinaria, encontramos en Alfred J. Ayer, ex-profesor de la Universidad de Londres y actualmente profesor on Oxford. Su libro Lan-

34 Cf. The Philosophy of Bertrand Russell, Schilpp's Library of Living Philosophers, Chicago, Northwestern University, 1944, p. 724. Cf. Hill, op. cit., esp. pp 61, 73 у 235. 
guage, Truth and Lógic, publicado en 1936 y desde entonces tema de innumerables debates en los círculos filosóficos anglosajones, contiene el cuadro fundamental de su pensamiento filosófico, definido por él mismo como un empirismo radical. Allí están expuestas también las ideas básicas del autor acerca de la ética y la teoría del valor - la concepción denominada unas veces emotivismo axiológico, otras nominalismo o escepticismo $\alpha$ xiológico, otras, en fin, imperativismo. Sólo ha vuelto a tratar el tema directamente en el ensayo "On the Analysis of Moral Judgements" 36 , introduciendo algunas modificaciones que no afectan lo más característico de su planteo.

La perspectiva en la que se sitúa Ayer es la del análisis del lenguaje. Emprende una crítica de la ética y la axiología cuyo objetivo central, tal como él mismo lo formula, es "mostrar que los enunciados de valor, en tanto son significativos, son enunciados 'científicos' ordinarios; y que en tanto no son científicos, no son en sentido literal significativos, sino simplemente expresiones de emociones que no pueden ser ni verdaderas ni falsas" ${ }^{\prime 3}$. Se trata pues de poner en tela de juicio la existencia de genuinas proposiciones sintéticas de tipo moral y, en general, axiológico. Para ello, el autor examina la composición de los sistemas de filosofía moral. Esta de ordinario no es homogénea. La conforman, según Ayer, cuando menos cuatro clases de enungiados: a) proposiciones que expresan definiciones de términos éticos o juicios acerca de la legitimíad ge posibilidad de ciertas définiciones; b) proposiciones que describen los fenómenos de la experiencia moral y sus causas; c) exhortaciones a la virtud moral; y d) juicios éticos efectivos ${ }^{38}$. Esta distinción ha sido generalmente ignorada por los investigadores de la ética, con la consiguiente oscuridad y confusión en los argumentos y conclusiones del debate filosófico. Una vez hecha, sin embargo, se aclara enormemente el problema de la filosofía moral, pues es fácil ver que la primera clase de enunciados, relativos a la definición de los términos morales, pertenecen a la ética filosófica, en cuanto invest1-

38 Horizon, septiembre de 1949, Cf., Ayer, Philosophical Essays, London, Macmillan, 1954.

37 Language, Truth and Logic, 2a. edición revisada, London, Victor Gollancz, 1951, pp. 102-103.

88 Ibid., p. 103. 
gación lógica del lenguaje moral, pero su naturaleza es analítica. Los enunciados de la segunda clase son del resorte de las psicología y las ciencias sociales, y no constituyen por tanto un dominio especial. Los de la tercera no son proposiciones, sino mandatos o expresiones destinadas a provocar ciertas reacciones en otros sujetos. Sólo queda pues por determinar el status del cuarto tipo de enunciados, el único que podría aspirar a constituir un dominio especial de proposiciones sintéticas o sea de juicios de valor.

Los intuicionistas piensan que tal clase de enunciados son 1rreductibles a conceptos empíricos y que su validez es intrínseca y está controlada por una intuición de género especial. Ayer considera inaceptable esta aseveración que, como sabemos, es la piedra angular de la tesis objetivista. Sin embargo, acepta la primera parte de la explicación. Cree que en ningún caso se pueden tratar los enunciados normativos axiológicos como proposiciones empíricas. He aquí lo esencial de su argumentación: "Rechazamos, dice, el punto de vista subjetivista según el cual llamar a una acción correcta o a una cosa buena es decir que es generalmente aprobada, porque no es internamente contradictorio sostener que algunas acciones generalmente aprobadas no son correctas, o que algunas cosas que son generalmente aprobadas no son buenas, i Trechazamos el punto de vista alternativo de los subjetivistas según el cual un hombre que sostiene que cierta acción es correcta o que cierta cosa es buena, lo que está haciendo es afirmar que él la aprueba, fundándonos en que un hombre que confesara que ha aprobado algunas veces lo que era malo o incorrecto no estaría contradiciéndose a sí mismo ${ }^{39}$. Una argumentación semejante desarrolla nuestro autor para descalificar las posicionès utilitaristas, que están ligadas estrechamente a las subjetivistas. "Desde que no es internamente contradictorio decir que algunas cosas agradables no son buenas, o que algunas cosas malas son deseadas, no puede ser cierto que la sentencia ' $x$ es bueno' equivale $a$ ' $x$ es agradable' 0 ' $x$ es deseado' " 40 .

La explicación cabal de los juicios de valor escapa según esto tanto a las teorías objetivistas cuanto a las subjetivistas y exige un tercer tipo de teoría, que es el que propone Ayer. Según

89 Ibid. p. 104.

40 Ibid., p. 105. 
él, los conceptos éticos y axiológicos son inanalizables y por tanto irreductibles a conceptos empíricos, lo cual no ocurre porque posean un contenido significativo especial, aprehensible por intuición, sino porque son pseudoconceptos. "La presencia de un símbolo ético en una proposición no agrega nada a su contenido factual. Así, si digo a alguien: 'Ud. obró incorrectamente al robar ese dinero', no estoy afirmando nada más que si hubiera dicho: 'Ud. robó ese dinero'. Al añadir que dicha acción es incorrecta, no formulo ningún enunciado adicional sobre ella. Estoy simplemente manifestando $\mathrm{mi}$ desaprobación moral al respecto. Es como si hubiera dicho: 'Ud. robó ese dinero' en un particular tono de horror, o si lo hubiera escrito poniendo un signo especial de admiración. El tono o los signos de admiración no agregan nada al sentido literal de la sentencia. Sirven tan sólo para mostrar que su expresión es acompañada de ciertos sentimientos en quien habla" 41 .

Lo mismo ocurre en todos los casos de enunciados de valor. La función de las palabras éticas no es por tanto significar objetos sino manifestar los sentimientos del hablante, o sea, una función puramente "emotiva". En algunos casos, ellas acompañan, con dicha función, proposiciones fácticas. Otras se dan en sentencias que expresan tan sólo el estado de ánimo del sujeto, sin implicar aserciones de hecho. Pero además cumplen una función adicional, que Ayer resaltaoene la plineraformulación de su teoría: una función retóriga Los términos yqlorativos están destinados a provocar ciertos sentimientos o reacciones en el oyente $y$ sirven de esta manera para estimular la acción de los demás. De allí que den a las sentencias en que aparecen un carácter imperativo; o sea que produce el efecto de mandatos. Por ejemplo, la sentencia: "Su deber es decir la verdad" puede ser considerada tanto como expresión de ciertos sentimientos subjetivos acerca de la veracidad, cuando como una orden, es decir, como equivalente a: "Diga la verdad". Se comprende además que hay una variada gama de expresiones correspondientes a los diversos tonos y estados de ánimo del sujeto que habla y a los efectos que se pretende provocar en los demás ${ }^{42}$.

Importa subrayar que, como el propio Ayer sostiene una y otra vez, no se trata de entender los enunciados éticos como pro-

41 Ibid., p. 107.

42 Ibid. p. 108. 
posiciones acerca del estado psicológico del hablante. La expresión de los sentimientos y la aserción relativa a tales sentimientos son cosas distintas, aunque a veces difíciles de diferenciar, porque se dan usualmente unidas en el lenguaje. Cuando alguien dice: "Estoy aburrido", está haciendo una afirmación sobre su estado de ánimo y, al mismo tiempo, expresándolo. Pero que esto no es lo mismo que aquello, lo muestra el hecho de que se puede expresar aburrimiento sin formular ningún enunciado ni usar lenguaje articulado ${ }^{43}$. Todo el sentido de la tesis de Ayer reside en esta distinción, pues, como queda dicho, según nuestro autor los enunciados valorativos no significan nada, no implican aserción alguna scbre hechos externos o estados anímicos, sino que son meras expresiones.

Se hace claro entonces que no sean aplicables a ellos las categorías de verdad y falsedad y que sea imposible verificarlos. Allí donde nada se enuncia, nada puede ser confirmado o rectificado. Dos conclusiones dignas de ser destacadas se siguen de esta tesis. La primera, que parece salir al encuentro de la experiencia cotidiana, es que no cabe disputar sobre cuestiones axiológicas y éticas. Cuando ocurren esta clase de disputas, piensa Ayer, en realidad se está discutiendo sobre cuestiones de hecho o de interpretación del lenguaje. Aclarado y resuelto este diferendo y enfrentados los oponentes a los enunciados éticos propiamente dichos, ño cábe ya discusión posible, pues en ellos no se hace ninguna afirmación ${ }^{44}$. La segunda conclusión toca al contenido y taréa degla éticáfilosófica y, por extensión, de todas las dísciplinas axiológicas. Puesto que los juicios morales son sólo expresiones de sentimientos, la investigación ética no puede aspirar a elaborar un sistema "verdadero" de moral ${ }^{45}$. No existe tal sistema, ni hay un dominio de objetos especial correspondiento a los términos valorativos. De allí que para Ayer todo intento "de hacer de nuestro uso de los conceptos éticos y estéticos la base de una teoría metafísica acerca de la existencia de un mundo de valores, diferente del mundo de los hechos, envuelve un falso análisis de dichos conceptos" ${ }^{\prime \prime}$. Puesta aparte la investigación psicológica y sociológica, no podría pues señalarse, como contenido y tarea propios de la ética y las disciplinas axiológicas, si-

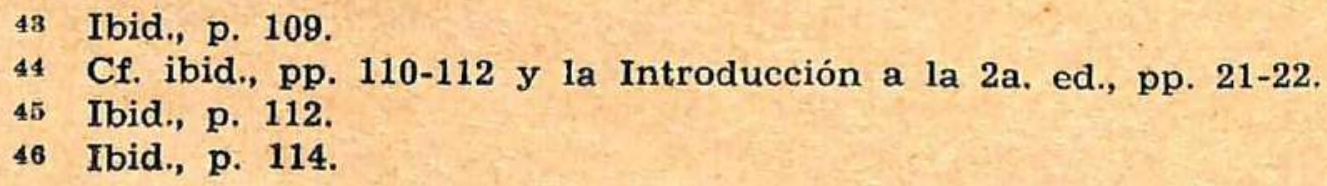


no la investigación lógico-lingüística de los sistemas morales y valorativos, con miras a su esclarecimiento y depuración formal.

Esta posición radical significó una saludable reacción contra las exageraciones del pensamiento especulativo y las confusiones del psicologismo. Sin embargo, apoyándose como se apoyaba en el análisis del lenguaje, implicaba un abandono casi total del uso común del lenguaje y, con él, del contenido de la experiencia moral. De allí que haya suscitado muchas objeciones y no sólo entre los representantes del pensamiento tradicional. En la propia dirección de la nueva filosofía británica, cuyo interés es también predominantemente lógico y lingüístico, han surgido intentos de superarla y de abrir así un nuevo cauce a la reflexión ética. Estos nuevos enfoques son los que hemos de considerar a continuación.

6.-Los nuevos planteamientos éticos: Toulmin, Nowell-Smith, Hare. Bajo la influencia de la filosofía lingüística se ha desarrollado en los últimos años en la Gran Bretaña un interesante movimiento de investigación en el campo de la ética teórica, cuya intención profunda es lograr una más fiel tradueción de los hechos del lenguaje y de la experiencia moral y, gracias a ella, superar los impasses a los que fue conducida la reflexión filosófica anterior. A manera de ilustración de esta corriente de ideas, quisiora llamar especialmente la atención sobre los trabajos de tres de los investigadores que han destacado en el período que se inicia después de la guerrajo Stephen Toulmin, de la escuela de Cambridge, y P. H. Nowell-Smith y Richard H. Hare, de Oxford.

Toulmin formula su posición en el libro An Examination of the Place of Reason in Ethics, del cual se ha dicho en Inglaterra que "es problablemente el más importante libro sobre ética publicado en este país desde Principia Ethica de Moore". (Times Educational Suplement). La tarea que el autor se propone allí es plantear y responder la pregunta: ¿qué clase de argumentación podemos aceptar como válida en respaldo de las decisiones morales? Hay implícito en este planteo un desafío filosófico a las posiciones dominantes hasta entonces en la ética, las cuales, - bien no consideraban el problema de la razón ética como el tema principal de toda indagación filosófica, o bien daban por cancelado cualquier intento de formular los problemas morales en términos de validez racional.

Toulmin no ignora ninguna de estas posiciones, ni el resultado del debate entre ellas. Por el contrario, considera necesario 
someterlas a un nuevo examen, capaz de hacer justicia a sus aportes positivos y decidir acerca de su aptitud para servir de base al tratamiento del problema que lo ocupa: el lugar de la razón en la ética. El análisis de Toulmin se concentra en las tres posiciones básicas que hemos reseñado en las páginas anteriores de este trabajo: el objetivismo, el subjetivismo y el imperativismo. Piensa Toulmin que ninguna de ellas ha abordado directamente el problema de la validez racional ética; han adoptado más bien respecto a él una visión oblicua, cuyo término directo era la cuestión del sentido de lo "bueno" y lo "recto". No se han preguntado qué queremos decir $\mathrm{y}$ en qué nos fundamos al afirmar que tal - cual argumento es una "razón válida" para la acción moral, sino qué cosa es lo bueno y lo correcto de que hablamos en el lenguaje moral. Pensaban que al responder a esto último se habría ganado por añadidura un criterio para encarar la cuestión de la validez racional de la conducta.

Ahora bien, el resultado de esta visión oblicua ha sido negativo. Con independencia de sus tesis finales, la manera de abordar el problema ha llevado a las tres corrientes mencionadas a fallar la verdadera cuestión en debate. Afirmando unas, como las objetivistas no naturalistas, la necesidad de una intuición de lo bueno y lo correcto, han fundado la cuestión de la validez de la acción en la existencia de una especie de propiedades, los valores, que, en la práctica, apuesto que resultan enormemente discutibles, no pueden serviri delfundamentos $a$, la conducta. Toulmin les reconoce a estas posiciones el haber visto bien que hay un innegable rasgo de objetividad en los enunciados morales y que, por tanto, cabe plantear la cuestión de su validez objetiva; pero han confundido esta cuestión con una cuestión de existencia e intuición de propiedades. Otros, como los subjetivistas, han confundido lo bueno y lo correcto con otro tipo de instancias, las "relaciones subjetivas", y siguiendo este camino han sido obligados a sustituir la cuestión de la validez por la cuestión de la actitud personal frente a las conductas y los hechos. Por su parte, los nominalistas, o imperativistas, como prefiere llamarlos Toulmin, al destacar el momento exclamativo y retórico que hay en las expresiones valorativas, han perdido de vista el problema de la validez de la acción que, pese a las teorías, se plantea en la vida normal de los hombres. Por cierto que - piensa Toulmin - tanto los subjetivistas como los imperativistas están en lo justo al llamar la atención sobre los elementos de actitud y la expresión de emo- 
ciones implicados en el lenguaje moral, pero el extremismo de su posición les ha ocultado el verdadero sentido de la cuestión racional práctica.

Es interesante señalar que Toulmin descubre, en la base de las tres posiciones y a despecho de su enfrentamiento mutuo, la aceptación de una misma premisa falsa, que lleva a las tres doctrinas por igual a la comisión de una falacia. "La plausibilidad de la doctrina objetivista -escribe Toulmin - reposa en la premisa (ordinariamente no formulada - suppresed) de que, si hay una contradicción entre dos personas, debe haber por lo menos una propiedad de algún tipo sobre la cual se contradigan; de otra manera, el juicio habría de ser sólo personal, referido al estado psicológico del sujeto hablante. La premisa es también tácitamente asumida en la argumentación a favor de la doctrina subjetivistá. Ahora bien, el abogado de la doctrina imperativista está bajo la tiranía de la misma idea: que para ser lógicamente respetable; para ser capaz de ser considerara 'Verdadera' o 'falsa', o para que haya un raciocinio acerca de ella, una sentencia debo estar constituída solamente por conceptos que se refieren a algo, a algo 'en el objeto' o 'en el sujeto'. La novedad de su paralogismo está en que rechaza ambas alternativas; reconoce que las sentencias y los conceptos éticos no 'se refieren' a nada, a ninguna instancia del tipo requéridoj at congluye. . que sólo pueden ser 'pseudo-proposiciones' ' pseudo-conceptos" 47 Para Toulmin, en cambio, la premisa es falsa y de su aceptación se derivan todos los problemcist que en sus últimas consecuencias plantean las tres doctrinas. Es un hecho que existe una contradicción allí donde hay un desacuerdo ético entre las personas. Pero aquello sobre lo que éstas se contradicen no es "nada física o psicológicamente 'concreto' o 'substancial', sino algo que, para los efectos lógicos, es por cierto igualmente sólido e importante, a saber, si hay o no una buena razón para llegar a una determinada conclusión ética más bien que a otra" 48

La crítica de Toulmin se condensa en la siguiente conclusión, a la vez afirmadora del momento positivo de las doctrinas tradicionales y canceladora de su operancia filosófica: los enunciados de los objetivistas, subjetivistas e imperativistas acerca

\footnotetext{
47 Toulmin, An Examination of the Place of Reason in Ethics, Cambridge, at The University Press, 1950, p. 57.

48 Ibid., p. 57.
} 
del sentido de los términos éticos son "comparaciones disfrazadas" ${ }^{\prime 2}$. Su base es la semejanza que en ciertos respectos hay entre, v.g., lo bueno y las propiedades, de un lado, y lo bueno y las relaciones subjetivas o las exclamaciones, de otro lado. Su error es pasar subrepticiamente de esta determinación a la afirmación de identidades, con lo cual se desnaturalizan los hechos morales y se arriba a consecuencias teóricas y prácticas inaceptables. Con este enjuiciamiento final, esas doctrinas quedan invalidadas como sistemas interpretativos de la vida moral; en lugar de enmendarlas, piensa Toulmin, es aconsejable rechazarlas llanamente. $Y$ es que, a decir verdad, mejores resultados que los de estas ambiciosas teorías axiológicas pueden obtenerse por una tarea más simple y modesta: la descripción de los conceptos morales; ella es capaz de proporcionarnos todo lo que necesitamos para entender la experiencia ética y para abordar la cuestión central de la validez de nuestras decisiones ${ }^{60}$.

El tratamiento temático de esta cuestión, al cual está dedicada la parte que llamaríamos constructiva del libro de Toulmin, requiere un cuidadoso análisis lógico de los tipos y funciones del razonamiento. Este abordaje permite a Toulmin comparar la ética y la ciencia, mostrando al hacerlo sus puntos de contacto lógicos y también diferenciando la misión y sentido de ambas. Se descarta asi su identificación simple e-igualmente las falsas posiciones y negaciones. Por ejemplo, aunque use la retórica, la ética no es purá retórica, affe de persuadir, como quieren hacer creer los emocionalistas o imperativistas, ni se opone en esto a la ciencia; la ciencia por su parte tiene también algo de retórica, lo que no invalida su carácter racional. Hay de hecho una inferencia moral, según Toulmin, y ella, como ocurre con toda especie de lógica, extrae su naturaleza propia de los fines para los cuales sirve. Considerada en su esfera y su función propias, la inferencia ética consiste en el paso de ciertas razones factuales (R) a ciertas conclusiones éticas (E). Al ser establecido en el discurso moral, este enlace tiene la virtud de provocar una alteración en la experiencia vivida. De esta suerte, cuando una conducta queda racionalmente validada, las vivencias precedentes, relativas a esa conducta, varían. Lo que primero nos parecía, por ejemplo,

19 Ibid. pp. 190-191.

so Cf. ibid., pp. 194-195. 
de que reclmente es correcto $\mathrm{y}$, psicológicamente, nuestra reacción al respecto cambia por completo. Contrariamente, la expliincorrecto, resulta luego una apariencia reemplazada por la idea cación científica, que permite prever los fenómenos, no altera el contenido vivido de nuestras experiencias. La percepción ilusoria de una vara quebrada en el agua no varía cuando hemos explicado el fenómeno. Por otra parte, las relaciones establecidas en el razonamiento ético no son conexiones que se ofrecen como aceptadas sólo por un sujeto y limitadas a él; son conexiones dignas de ser acepladas universalmente, sin consideración del sujeto singular de la acción. Con ello se prueba que hay una objetividad racional ética indudable, como la hay en la lógica de la ciencia, y que comparte con ésta una esencia común que está dada por las nociones que Toulmin llama gerundive concepts (conceptos "gerundivos"), coma v. g. lo bueno y lo correcto, a cuya clase pertenece justamente también la categoría de lo verdadero ${ }^{51}$.

Para Toulmin, la ética se ocupa de la satisfacción armoniosa de los deseos e intereses en la vida en común con otros hombres, pues las nociones de deber y moralidad han surgido de las situaciones sociales en las cuales la acción de una persona puede perjudicar a otras. Ahora bien, la lógica del raciocinio moral se adecúa a esta función. La argumentación ética opera unas veces por remisión de la acción que se quiere fundar a una práctica aceptada como beneficiosa, o sea, a una regla de conducta. Otras veces, cuando hay conflictos de deberes o se pone en tela" de juicio un principio o práctica social, la buena razón para obrar se obtiene considerando si la alternativa por la que se quiere optar afectará a los demás o logrará disminuir el mal y mejorar la vida ${ }^{52}$. Estas dos posibilidades constituyen el esquema básico de la justificación de la conducta. Dentro de semejante marco, la lógica ética opera con toda eficacia. Pero no cabe ya usarla más allá de él, porque aquí, como en la ciencia, hay cuestiones que no pueden plantearse ni por tanto resolverse estrictamente. Entre éstas se cuentan justamente las que tocan a los presupuestos básicos, o sea, a los términos por los que se define el sistema lógico mismo, y también las que tradicionalmente ha abordado el pensamiento figurativo y la religión, con una finalidad de consuelo y apasiguamiento espiritual.

61 Ibid. pp. 70-72.

62 Ibid. pp. 144 ss. 
No habrá dejado de advertirse que esta formulación del papel de la ética y la función de su lógica, aunque hecha por Toulmin con una intención meramente descriptiva, está muy cerca del punto de vista utilitarista. Con ello se hace presente una problemática filosófica que rebalsa el planteamiento de Toulmin y que merecería un análisis especial encaminado a determinar hasta qué punto afecta las conclusiones del libro. Esta es una tarea que escapa a las intenciones y los límites de esta reseña. Pero esto no invalida el esfuerzo que la obra de Toulmin comporta de recuperación de categorías tan importantes como las de validez lógica y verdad, que parecían definitivamente desterradas de la filosofía moral por la crítica neopositivista.

La lógica del lenguaje ético, tal como es usado en el contexto de la vida cotidiana de los individuos y los grupos, es también el tema central del libro Ethics de P. H. Nowell-Smith, distinguido representante de la filosofía analítica británica que tiene en Oxford su foco de irradiación. No es posible dar cuenta cabal en estas breves páginas del rico contenido descriptivo y lógico de la obra mencionada. Hemos de limitarnos por eso a poner de resalto algunos de sus desarrollos principales y las conclusiones críticas a que conducen. Destaca en primer lugar el estudio dedicado a la lógica de los adjetivos, con la importantísima distinción establecida entre las palabras que el autor llama descriptivas (descriptive-words), v.g., rojo, cuadrado; las palabras de aptitud (apinesswords), las cuales indican que un objeto posee ciertas propiedades capaces de provocar determinado tipo de emociones, y las palabras que, al igual que Toulmin, designa como "gerundivewords", o palabras "gerundivas", cuyo sentido indica que algo es digno de ser apreciado, notado, aceptado, etc., como es el caso v.g. de "estimable", "laudable" y otras de la misma suerte53. Esta distinción, tal como opera en el lenguaje ordinario, es necesaria para entender rectamente el discurso práctico. Pero como el uso de estas palabras se concreta en sentencias y argumentos, Nowell-Smith considera indispensable examinar también la lógica de estos enunciados en la esfera práctica $y$, desde esta perspectiva, revisar el alcance de las categorías y clasificaciones de la lógica general. Este análisis lo conduce a proponer los conceptos (ya, por lo demás, apuntados por Moore) ${ }^{54}$ de implicación

b3 P. H. Nowell-Smith, Ethics, Penguin Books, 1954, pp. 70 y ss.

o4 Cf. "A Replay to my critics", pp. 540 y ss. 
contextual y extrañeza o rareza lógica (logical oddness), en reemplazo de los de implicación lógica o conexión analítica y contradicción interna. He aquí cómo el autor formula el sentido y aplicación de estos nuevos conceptos: "Diré que una proposición $p$ implica contextualmente $q$, si quienquiera que conozca las convenciones normales del lenguaje está autorizado a inferir $q$ de $p$ en el contexto en que ellas se dan. Las implicaciones lógicas son una sub-clase de las implicaciones contextuales, desde que si $p$ implica lógicamente $q$, estamos autorizados a inferir $q$ de $p$ en cualquier contexto que sea"55. "Diré que una pregunta es "lógicamente extraña' (logically odd), si resulta no haber lugar para ella en su contexto porque ya ha sido respondida. Eslo no equivale a decir que la pregunta sea necesariamente sinsentido, sino que estaríamos desconcertados respecto a su sentido y tendríamos que darle una interpretación insólita"se. Por ejemplo, si cuando alguién dice "Está lloviendo", inferimos de esta sentencia que dicha persona cree que esta lloviendo, estamos haciendo una inferencia legítima a base de una implicación contextual, aunque el enunciado "X cree que está lloviendo" no se siga lógicamente del primero. $E$, inversamente, no nos sentiremos autorizados a decir, a base de aquella misma sentencia: "X no cree que está lloviendo", aunque no haya contradicción entre esta sentencia y la primera, porque sería lógicamente extraño que una persona afirmara: "Está lloviendo, pero no creo que esté lloviendo" ${ }^{57}$.

La existencia de palabras con uso de aptness-words ( $A$-words) y de gerundive-words (G-words) abre la vía para la determinación de los correspondientes tipos de sentencias ( $A$ y G-sentences), indispensable para entender, dentro de la red de las relaciones contextuales, el sentido del lenguaje colidiano. Lo mismo ocurre con las que Nowell-Smitn llama palabras "pro" y "contra" (pro y con-words), relativas a las actitudes de los sujetos hablantes, que se vinculan a su vez con sendas clases de sentencias ${ }^{58}$. Estas por su parte abren la vía para esclarecer la función y alcance de la elección práctica, cuyo centro de gravitación lingüístico, por así decirlo, es la pregunta "¿Qué he de hacer?" (What shall I do?).
65 Ibid., p. 80.
60 Ibid., p. 83.
of Cf. ibid., p. 81.
68 Cf. ibid., 112 y ss. 
Sobre la base de estas consideraciones lóglico-lingüísticas, auxiliadas por finos analísis psicológicos, Nowell-Smith aborda el estudio de los conceptos y situaciones típicamente morales (deber, obligación, rectitud, bueno) y los problemas tradictonales de la conciencia, la responsabilidad y la libertad. Con ello busca ofrecer no una doctrina cerrada de la vida moral, ni menos aún un decálogo para la acción personal, sino un esclarecimiento del discurso práctico en la interna conexión de sus conceptos, capaz de servir como instrumento crítico para elaborar las propias decisiones y superar las dificultades que un pensamiento unilateral y simplista puede hacer surgir en la experiencia cotidiana. De allí que al final del libro haga hincapié en la necesidad de precaverse contra las confusiones lógicas derivadas precisamente de la especulación filosófica que estaba llamada a eliminarlas, que impiden, con su seductora apariencia de verdad, comprender de modo recto los fenómenos morales.

Reseñar estas confusiones será una buena manera de presentar en síntesis las conclusiones críticas del libro de Nowell-Smith. Las principales de ellas, tales como el autor las enumera, son las siguientes: 1) la transferencia a las discusiones sobre el discurso moral de conceptos que son aplicables en la elucidación del discurso matemático o científico. Esto ha inducido a pensar que la tarea de la ética era descubrir verdades teóricas sobre la naturaleza humana o un reino especial de valores. Este error, combinado con la comprobación de que las verdades de hecho no implicon imperativos y que ni éstos nil aquélla's implican decisiones, ha conducido a la doctrina de que las palabras morales se refieren a entidades especiales y a la postulación de una facultad especial, la intuitiva, como fuente de las verdades morales. Se ha perdido así de vista la verdadera diferencia entre el discurso teórico y el práctico, confundiéndola con una diferencia entre clases de objetos. Ella es en cambio una diferencia en la función desempeñada por diversos tipos de expresión. 2) Por otro lado, se ha olvidado el fondo contextual del uso de las palabras, las variadas implicaciones de sentido que las mismas palabras pueden tener en diferentes situaciones vividas, lo cual ha llevado a conformarse con análisis parciales del significado de los términos. Se da de este modo la paradoja de que unos autores consideran un truísmo lo que otros tienen por completamente falso; los unos han tratado una clase de conexiones lógicas como válidas en todos los contextos, mientras que los otros han hecho lo mismo con 
una clase distinta. 3) La polémica entre los teleologistas y los dentólogos muestra que los primeros, al intentar definir las palabras deontológicas en términos de propósitos, felicidad, deseo, placer o bien, han confundido las cuestiones lógicas acerco del sentido de las porlabras "deber", "recto", "justo" u "obligatorio", con las cuestiones prácticas ccerca de qué reglas debemos adoptar y con las psicológlcas relativas a qué actitudes favorables tienen de hecho los hombres. Contra ellos tienen rorón los dectólogos al denunciar este proceder como incapaz de dar cuenta de la función que los conceptos deontológicos desempeñan en el elegir. aconsejar, ordenar y exhortar: Pero los deontólogos, por su parte, han exigido separar tan tajantemente estas cuesthones, que har. sido llevados a tratar deseos y propósitos como conceptos meramente empíricos, que no importan al investigador de la moral, y a sostener la extravagante afirmación de que la filosofía moral tradicional reposa en un error. Sin dificultad podría en cambio hacerse justicia a ambas posiciones distinguiendo el punto de vista del legislador y el punto de vista del juez. 4) El tratar toda pro-actitud, es decir, toda respuesta lógicanente completa a la pregunta "¿qué he de hacer?". como cuestión de deseos o inclinaciones - que es lo que han hecho los subjetivistas- no sólo ha dado como resultado una psicología simplificada al extremo, sino que ha hecho también inevitable el considerar toda acción voluntaria como egoísta. Esto, por oposición, ha conducido -como ocurre en el caso de las filosofos intuicionistástalos tratar el sertido del deber como una fuerza no-nqtural De esta manera las discusiones doctrinarias se mueven en el terreno de las puras presunciones y desembocan en afirmactones contrarias a lo que de cierto sabemos acerca del hombre $y$ su conducta ${ }^{s s}$.

El esclarecimiento lógico de las confusiones filosóficas no está destinado por lo demás a decidir cúál de las teorías tiene la razón, ni a declararlas infundadas completamente; su propia persistencia como teorías basta para probar que no son errores totales. Pero sí puede hacerlas inotensivas $\mathrm{Y}$ eliminar los obstáculos pueslos a la comprensión de la praxis moral. La reflexión ética tiene de este modo preparado el camino para su función positiva, que será lanto más eficaz cuanto más ampliamente cubra el dominio de Ia experiencia y la vida moral del hombre $\mathrm{y}$ en su contexto abor-

s9 Tbid. pp. $317-319$. 
de las interrogaciones sobre el sentido de la acción. Tiene sin embargo límites que no pueden ignorarse. "La filosofía moral -escribe Nowell-Smilh- es una ciencia práctica; su meta es responder a las preguntas de la forma "zqué he de hacer?". Pero no se puede dar ninguna respuesta general a este tipo de preguntas. Lo más que un filósofo puede hacer es trazar un cuadro de los diferentes tipos de vida al modo de Platón, y preguntar qué clase de vida se quiere llevar. Pero ésta es una peligrosa tarea por emprender, porque la clase de vida que se quiere llevar depende de la clase de hombre que se es. Las decisiones y los imperativos no se siguen lógicamente de las descripciones biológicas y psicológicas; pero la clase de vida que de hecho será satisfactaoria para un hombre depende de la clase de hombre que es" En último término, luego de haber alcanzado la comprensión correcta de los problemas de la conducta. las preguntas zqué he de hacer? y ¿qué principios morales debo adoptar? $y$, con ellas, las decisiones fundamentales deben pues ser abordadas por cada hombre de acuerdo a sus propias convicciones.

Richard M. Hare, actual docente en Oxford, ha hecho también una notable contribución al estudio de los temas éticos desde el punto de vista lingüístico en su libro The Langugge of Morals y en otros trabajos breves. Hare distingue claramente los temas propiamente ético-filosóficos de aquellos que, aunque tradicionalmente vinculados con la filosofía rioral, no le corresponden estrictamente. A juicio suyo. la ética no debe abordar cuestiones del tipo de "¿debo hacer estre?"Plocclies líc poligamia incorrecta?", es decir, cuestiones morales, nt lets cuestiones de hecho locantes a las opiniones, costumbres, apreciaciones morales de los individuos o los grupos, sino las que conciernen al sentido de las palabras morales o a las cosas a las que dichas palabras se refieren. Estas últimas cuestiones y la temática vinculada con ellas son las que conviene denominar éticas. Ellas determinan el campo en el que se desenvuelven. como un lipo independiente de quehacer té́rico, las investigaciones propiamente filosóficas en relación con la moral así como seurre con las demás formas de la filosofía cuya esencia es el antílisis conceptual" Con ello, piensa Hare. no se restringe indebidamente ni menos se desvirtúa la función de lá filo-

to Ibid, pp. $319-320$.

H Cf. el articulo Ethies, in Encyclopedia of Philosophy and Philosophers, ed. J. $O$. Ummsom. 
sofía. Esta ha sido siempre primariamente -como el ejemplo de Sócrates lo prueba- análisis de conceptos, esclarecimiento del sentido y las implicaciones de las expresiones que usamos en la vida ordinaria $y$ en las cuales se traduce nuestra relación con el mundo.

Hare adopla el punto de vista del prescriptivismo ético, según el cual los términos morales poseen, además de un sentido descriptivo, un especial sentido evoluctivo. Este contentdo significativo -tal como lo analiza Hare en el artículo Ethics ya mencionado- determina que los juicios morales, o semejanza de los imperativos, comprometen al sujeto que los enuncia "con cierto tlpo de precepto o prescripción acerca de una decisión o elección efectiva o concebible".

Uno de los rasgos característicos de esta tesis es que permite restablecer el carácter auténticamente judicativo de los enunciados de vaior que el emotivismo había negado. El hecho linguístico está lejos de autorizar esta negación, pese a que el emotivismo parece derivar toda su fuerza del analisis del lenguaje. Es particularmente errónea y peligrosa la interpretación que dicha teoría ofrece de los términos morales y su uso como vehículos de persuasión. Si éste fuera el caso, piensa nuestro autor, no habría diferencia entre el lenguaje moral y la propaganda" Pero que no es el caso lo pruebo el hecho de que el discurso moral. sín perder su calidad de tal, puedo estar exento de todo elemento persuasivo $y$ emplearse ho sblo sin propósito de intluit en el oyente, sino también sin efectós de estac clase.] Y $Y$ estopopurre porque la persuasión, es decir, la retorica, apela al sentimiento, trata de desencadenar ciertas energías irracionales, mientras que los enunciados morales se usan para responder cuestiones formuladas por angentes racionales. $y$, al igual que los enunciados descriptivos, están gobernados por reglas lógicas ${ }^{03}$.

A semejanza de los dos investigadores que acabamos de estudiar, en Hare esta recuperación de la categoría lógica de juicio dentro del dominio del lenguaje moral $y_{1}$ en consecuencia, también la de validez, no se efectúa por una reducción de los enunciados morales a proposiciones psicológicas o sociológicas, al esti-

\footnotetext{
e2 R. M. Hare, The Language of Morals, Oxford, at The Clarendos Press, 1952, pp. 14 y 55.

ti Ibid. pp. 15-16.
} 
lo del subjetivismo, ni tampoco por una vuelia a las viejas posiciones objelivistas. Hare descarta por igual ambas soluciones. Su voluntad de ir más allá se patentiza en el rechazo que hace inclusive de la dicotomía subjetivismo-objetivismo que, según él, tal como es formuladic ordincriamente, está fundado en un incorrecto andilisis del lenguaje.

El concepto de validez no puede ser descartado de la ética justamente porque la interrogación "¿qué he de hacer?" constituye un momento fundamental del lenguaje moral $Y$ no puede ser evadida en la práctica. Por su carácter prescriptivo, los enunciados morales procuran razones para la acción. No hay enunciado moral propiamente dicho sin esta orientación de la acción. La functón de la ética filosófica es por tanto abordar la problemática lógica planteada por este carácter esencial de los enunciados éticos y de valor. Hare lo hace en The Language of Morals o través de un penetrante estudio de la lógica de los imperativos, en primer término, y luego, de la lógica correspondiente a las palabras valorativas $y$ a las sentencias en que éstas aparecen. Esto le permite rectificar las erróneas interpretaciones aceptadas en las teorías éticas precedentes. Entre ellas, es especialmente inportante la que busca reducir las enunciaciones morales a sentencias indicativas. Piensa Hare que si se hiciera esto quedaría cerrada la vía para realizar legítimas inferencias morales. En efecto, de acuerdo \& la lógiea imperativa - no puede derivarse una conclusión imperativa a partir de una proposición descriptiva. Si no hay en las paremisas porciloemenosinurgmperativo, la conclusión imperativa se alcanzará por un salto ilegítimo, como ya lo había notado Hume $y$ ha sido acentuado en la crítica moderna de la falacia naturalista. Esto quiere decir que hary un elemento en el lenguaje imperativo que no puede reductrse al modo indicativo $y$ es justamente este elemento el que permite el uso del lenguaje moral y las inferenclas que en la práctica hacemos. Este elemento diferencial es lo que el prescriptivismo resalta.

Lo mismo ocurre con las palabras y sentencias valorativas. Todo intento de reducirlas a términos meramente descriptivos desvirtúa el lenguaje axiológico. Pero no otra cosa es lo que hace el naturalismo en sus diversas variontes. Por cierto que el análisis de Hare muestra que las palabras axiológicas tienen también un sentido descriptivo y que este elemento sirve de cpoyo cl uso de tales palabras con intención de alabar, decidtr, apreciar $y$, en ge- 
neral a toda forma de empleo valorativo del lenguaje. Pero, como io muestra el anćlisis de "bueno", en el lenguaje moral el contenido primario de la significación de dichas palabras es el evalualivo, por el cual se recomienda o encomia un acto o un objeto ${ }^{\text {Bt }}$. Dicho momento es pues fundamental e irreductible ya que sólo gracias a él es posible comprender este rico dominio del lenguaje, con todos sus malices y variedades prácticas.

El naturalismo y su falacia característica pueden descubritse $y$ controlarse por atención a este elemento, pues todo intento de suprimirlo - que es por los demás frustráneo- lleva inevitablemente a esc falacia. Hare aconseja emplear el siguiente procedimienta para revelar cualquier variedad de naturalismo: "Supongamos que alguien sostiene que puede deducir un enunciado moral u otro evaluativo cualquiera a partir de un conjunto de premisas factuales o descriptivas, sirviéndose de una definición por la cual V (una palabra valorativa) significa lo mismo que $\mathrm{C}$ (un complejo de predicados descriotivos). Primeramente tenemos que preguntarle si está segura de que $C$ no contiene ninguna expresión que sea embozadamente evaluativa (por ejemplo 'natural' o 'normal' o 'satisfactorio' o 'necesidades humanas fundamentales' ). Casi todas las llanadas 'definiciones naturalistas' se desbaratan ante este prueba; porque unơ definición, si ha de ser genuinamente naturalista, no debe contener ninguna expresión cuya aplicabilidad carezca de un griferio definido que no envuelva Ia formulación de un juicio de valor. Si la definición satisface esta prueba, hemos de preguntar luegeses bu cabogadoodesele fecomendar alguna vez algo por ser C. Si dice que sí, basta con indicarle que su definición imposibilita esto por las razones dadas. $Y$ es claro que él no puede decir que no desea recomendor nunca algo por ser $C$. porque recomendar cosas por ser $\mathrm{C}$ es todo el objeto de siz teoría" $\mathrm{ar}$.

El análisis de Hare hace patente que la última ratio del edificio moral es la formulación de evaluaciones cuyo momento fundamental es la decisión de los principios prescriptivos de la conducta. Sin ella no hay discurso moral posible. Pero esta decisión no puede ser entendida $\sin$ la intervención activa de los sujetos singulares, agentes del comportamiento práctico. Aquí también, pues. como en las dos últimas doctrinas expuestas, el recurso final es

th Cf., op. cit. 7, pp. 111 y as.

65 Ibid., pp. 92-93. 
un acto personal el análisis filosófico no lo sustituye ni lo evita, antes bien lo hace necesarto, pues sin él no puede comprenderse el sentido evaluativo de las palabras y las sentencias. La decisión de los principios normativos de la conducta es atribución de cada hombre en las circunstancias caneretas de su vida. A esta functón se accede por la instrucción $y$ por la evolución personal. Cuando estám bien orientadas. la madurez a que nos llevan significa el justo equilibrio entre la acepiación simplemente habitual de los principios establecidos (que se ofrecen con la firmeza y perennidad que reivindicon los objetivistas) y la reivindicación adolescente (que correspondería a la tesis subietivista) del derecho a establecer nuevas normas y optar de acuerdo a los sentimientos singulares. "Llegar a ser moralmente adulto, escribe Hare, es reconciliar estas dos pasiciones, aparentemente en conflicto, aprendiendo a formular decisiones de principlo; es aprender a usar las sentencias de 'deber ser' comprendiendo que ellas sólo pueden ser verificadas por referencia a un patrón o conjunto de principios que hemos aceptado por nuestra propia decisión y que hemos hecho nuestros" "в.

El alcance práctico del anćlisis lingiuístico de la moral ha gido puesto de resctito por Hare aplicando sus conclusiones ol estudio de ciertos problamas morales concretos. Este es por ejemplo el caso de los problemas relativos a la obediencia de la outoridad y al deber patriótico. Ptensa Hare gue el recto entendimiento de lo que es una decision moral $y$ del aso de palabras tales camo "deber" y su derivadaspepenmitendeterrninger jos límites dentro de los cuales cabe aceptar ló resoluciones de la autoridad sin desoir las exigencias morales personales. Este límite es por cierto variable de cruerdo a las drcunstancias concretas, pero existe indudablemente. La aceptación del princlplo de autoridad y su volor prádtlco no anulan por eso el hecho de que hay "un momento en que el subordinado tiene que decir: 'cualquter plan que incluya el que yo haga exta clase de acciones ( toda esta gente a sangre frít) tiene que ser un plan perverso; $y$ cualquiera que lo conclba tiene que ser un perverso; y no puede. por tonto, ser mi deber obedecerlo'. Decidir cuándo llega ese momento es uno de los problemos más difíctles de la moral. Pero nunca proscribamos de nuestra mente la idea de que bien puede

an Ibid, pp. 77-7B 
llegar. Nunca perdamos de vista la diferencia entre lo que se nos dice que hagamos y lo que debemos hacer. Hay un límite más allá del cual no podemos sacudirnos nuestras responsabilidades morales echándoselas encima $a$ un superior, sec este general, sqcerdote 0 politico, humano o divina ${ }^{\prime \prime}$.

El examen de la cuestión de qué es lo que moralmente puede exigirnos nuestro país, da por su parte ocasión a Hare para mostrar que podemos circunseribir por una norma lógica el sentido $Y$ uso del concepto de "deber" $Y$ sefialar así los limites dentro de los que ciertas acciones son moralmente aceptables. Se trata del principio de imparcialidad que determina que un juicio sólo es moral si posee ciertos caracteres formales. Según éstos, la exigencia moral expresada en un deber no puede referirse a condiciones singulares, ligadas con unas personas y no con otras, sino a una situación o a una cierta condición genérica. La norma moral debe establecer pues algo imparcial con respecto a Jas personas, o sea, no debe contener terminos singulares ineliminables. "St yo mantengo que es mi deber hacer cierta acción, pero digo que otra persona, que se halla en exactamenfe las mismas dircunstancias, no tiene el deber de hacer una acción semejante. estoy diciendo algo gue es lógicamente raro y da margen para sospecharse que no entiendo plenamente el significado de la palabra 'deber'. Cuando algo es el deber deflouien, esto es así por algo en la situación en que se encuentra"ns. Así, no se puede considerar debér pafriótico moral ningund acción respecto de la. cual no estamos dispuestos a admitir que también está obligado a realizarla cualquier ciudadano de otro país, inclusive un país enemigo. No hay deber moral patriótico que sea tal porque se refiere a nuestro país y sólo a él.

Hare sefíala con razón el perentesco de este principio con el imperativo categórico kantiano, del cual se diferencia sin embargo porque es estrictamente lógico. El principio de imparcialidad, en efecto. no es moral en ningún respecto, pues no comporta ninguna evaluación. Esto justamente hace que tenga un alcance li mitado y pueda ser evadido mediante artificios inobjetables lógica-

\footnotetext{
คT "Etica y política", traducción de Héctor Neri Castañeda; separata de la Revista de la Universidad de la Universidad de San Carlos, p. 140 .
}

as

Ibid., p. 142 . 
mente. Por ejemplo, un caníbal decidido a sostener la tesis de que es deber suyo el matar a los hombres de olras tribus, para asegurar la alimentación de su gente -un "primitiviste", como lo coljfica Hare--m. podría decir que la norma que él propugnal no contiene términos singulares ineliminables, pues se refiere a los miembros de una tribu que genéricanente se diferencian de los demás. Y podría seń́alar como eritarios diferenciales los más arbitrarios rasgos y corcacteristicas (v.g. vestido, costumbres, elo.). El principio lógico de lo imparcialidád no puede nada contra esta argucia. Con ello se manifiesta un límite del control lógico de la morchljdad y se hace clara la necesidad de complementar este proceder por el recurso a olros principios. Estos, por contener evciluaciones, pueden permitir derivaciones morales de alcance más universal, aunque su compulsividad sea menor que la de los principios lógicos. Este es el caso del principto que, en relación con el ejemplo señalado, Hare formula en estos términos: "Yo soy un hombre y no considero moralmente pertinentes las meras diferenclas de tribu entre yo y otros hombres"th. Este es un principio moral propiamente dicho $y$ permite convertir en una norma verdaderamente universal - lo que era justrmente le intención kantianalas exigencins de la conductr que puede reconocer cualquier ciudadano de un país. De acuerdo con él, lo que es válido para un hombre en su coción giudgdana protede de la condición general de hombre. respecto de la cual ho son pertinentes los particula-

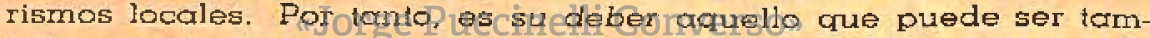
bién exigido de cualqujer otro hombre en relación con su país.

Según hemos dicho, al rebalsar los lírnites señalados por las condiciones Iógico-formales, los principios morales pierden fuerza de convicción. pues se remiten a la evaluación personal. Pero no por ello quedan anulados todas las posibiliderdes de lograr para ellos una universalidod de aceptación. A falta de los recursos formales, puede apelarse a otros complementarios y entre estos, piensa Hare, lo imaginación ocupa un puesto principal. Cuando ol "primitivista" deliende un principio que vale para su propia condición nacional y no para los ciudadanos de otros paises. sabe hacerle pensar en la posibilidad de quo él se encuentre en el lugar de esos atros ciudadanos, o sea, cabe llevarlo a ponerse por la imaginación en lugar de ellos. Y esta opercrión segura-

010 Ibid., p. 143. 
mente le impedirá defender sensatamente una norma moral que agravie a otros hombres. Es por eso que Hare afirma que "la imaginación es la facultad en que se funda la moralidad", aunque no ciertamente sólo ella. De allí que agregue: "la imaginación juntamente con el principio lógico que he estado defendiendo. Ninguno es por separado suficiente; pues si no nos diéramos cuenta de que los principios morales han de ser imparciales, de nada serviría imaginarnos cómo sería si nosotros fuéramos el otro; al revés, si no fuéramos capaces de situarnos con la imaginación en el lugar del otro, pudiéramos quedar satisfechos con principios lógicamente impecables... pero los dos juntos son mortales para el primitivismo"io.

Otros investigadores han aportado también en los últimos años valiosas contribuciones a la edificación de la teoría ética desde el punto de vista del análisis lógico. Este es el caso, entre otros, de S. Hampshire, Urmson, Mayo. Strawson y Montefiori. No podemos estudiar aquí la obra de estos pensadores, aunque es merecedora de la atención más cuidadosa. Sólo quisiera hacer notar que, en algunos de ellos, como Montefiori, se abre paso la conciencia de los límites inherentes a toda filosofía lógica, que son los límites históricos de los lengudjes mismos. Si no tiene conciencia de estos límites, la crítica ética basada en el anćlisis lógico, aunque ha mostrado ung gran fecundidad, corre el peligro de conceder vigencia universalla ciertas Conclusiones válidas sólo para determinados lenguajes. Se hacecpatente asíla necesidad de adoptar un punto de vista superior, capaz de situar debidamente la esencia social y cultural de la comunicación y sus interpretaciones, punto de vista que parece ser el de una crítica histórico-ftlosófica del hecho lingüístico.

7.-La orientación de la ética británica. El propósito principal del presente irabajo ha sido delinear las principales corrientes de la ética británica actual. No hemos expuesto por cierto todas las doctrinas que han surgido o se han desarrollado en el siglo XX y que animan la obra de muchos investigadores importantes. Así, por ejemplo, no hemos considerado las nuevas versiones del evolucionismo de cepa científica, como la que defiende Julián Huxley, o las de cepa metafísica, como es el caso de la filosofía de Samuel Alexander; las distintas variedades del neonaturalismo, representadas v.g. por la obra de Baier o Foot; el idealismo

70 Ibid., p. 149. 
teísta de Sorley y las teorías de la autorrealización, como la defendida por Muirhead.

A base de los filósofos y las doctrinas que hemos tratado. cabe sin embargo hacer una caracterización de los rasgos principales del pensamiento élico británico que permita precisar mejor su orientación general. A mi juicio, estos rasgos principales son: 1) Un interés dominante por la práctica concreta. La investigación ética se emprende $Y$ desenvuelve, sin menguc del rigor teórico, teniendo la mira puesta en la vida cotidiana. Es un intento declarado de clarificar y racionalizar la caccón. De allí que una teoría resulte objelable cuando la praxis ordinaria, por ingenua que sea, la desmiente. 2) La filosofía moral aspira a adoptar en lo posible procedimientos tan seguros camo los de la metodología científica. Este rasgo se comprende muy bien considerando las motivaciones prácticas del pensamiento inglés. Se quiere obtener resultados probadas y utilizables en la conducción del comportamienta diario, Y el mejor modelo de eficacia lo da lo ciencicr. Lo cual no quiero por cierto decir que la ética identifique su quehacer con el de la ciencia, pues las diferencias se hacen notar reiteradamente. 3) La opasición a las fundamentaciones rnetafísicas. Paralelamente al practiciamo, se da en efecto en los pensadores británicos una caracteristica actitud de reserva y recelo frente al pensamiento especulativo y la voluntad declaroda - aunque no siempre logradade no hacer reposar loo teoria ética en construcciones metorísicas. 4) La preocupación constante porel análisis del lenguaje desde una perspectiva "Logica. "Este rasgo se hace presente ya en la obra de Moore $y$, a medida que nos acercamos a la actualidad, domtna cada vez más la filosofía moral británica. Se puede inclusive decir que para los más representativos filósofos de hoy, la ética es esencialmente el análisis del lenguaje moral, así como, en general, la filosofía es el análisis lógico del benguaje. 5) La aten. ción puesta en las motivaclones hedonistas y utilltaristas de la práctica. La ética británica actual no renuncia a dar cuenta de estas motivaciones y a considerarlas momento fundamental de loda explicación de la conducta. Con lo cual se enlaza con una antigua iradición del pensamiento y la cultura de ese poís. Par cierto que puede decirse que la vinculación con ciertas orientaciones tradicioncles de la reflexión y la cultura no vale sólo para el áltimo de lon aspectos considerados, sino en general para todos, lo cual da a la filosofía británica su doble carácter de novedad y de firme enraizamiento en la historia. 